\title{
Self-voice perception and its relationship with hallucination predisposition
}

Citation for published version (APA):

Pinheiro, A. P., Farinha-Fernandes, A., Roberto, M. S., \& Kotz, S. A. (2019). Self-voice perception and its relationship with hallucination predisposition. Cognitive Neuropsychiatry, 24(4), 237-255.

https://doi.org/10.1080/13546805.2019.1621159

Document status and date:

Published: 04/07/2019

DOI:

10.1080/13546805.2019.1621159

Document Version:

Publisher's PDF, also known as Version of record

Document license:

Taverne

Please check the document version of this publication:

- A submitted manuscript is the version of the article upon submission and before peer-review. There can be important differences between the submitted version and the official published version of record.

People interested in the research are advised to contact the author for the final version of the publication, or visit the DOI to the publisher's website.

- The final author version and the galley proof are versions of the publication after peer review.

- The final published version features the final layout of the paper including the volume, issue and page numbers.

Link to publication

\footnotetext{
General rights rights.

- You may freely distribute the URL identifying the publication in the public portal. please follow below link for the End User Agreement:

www.umlib.nl/taverne-license

Take down policy

If you believe that this document breaches copyright please contact us at:

repository@maastrichtuniversity.nl

providing details and we will investigate your claim.
}

Copyright and moral rights for the publications made accessible in the public portal are retained by the authors and/or other copyright owners and it is a condition of accessing publications that users recognise and abide by the legal requirements associated with these

- Users may download and print one copy of any publication from the public portal for the purpose of private study or research.

- You may not further distribute the material or use it for any profit-making activity or commercial gain

If the publication is distributed under the terms of Article $25 \mathrm{fa}$ of the Dutch Copyright Act, indicated by the "Taverne" license above, 


\title{
Self-voice perception and its relationship with hallucination predisposition
}

\author{
Ana P. Pinheiro (1) ${ }^{a}$, António Farinha-Fernandes ${ }^{a}$, Magda S. Roberto (D) a and Sonja \\ A. Kotz ${ }^{\mathrm{b}, \mathrm{c}}$ \\ ${ }^{\mathrm{a}}$ Faculdade de Psicologia, Universidade de Lisboa, Lisboa, Portugal; ${ }^{\mathrm{b}}$ Faculty of Psychology and Neuroscience, \\ Maastricht University, Maastricht, Netherlands; ' $M a x$ Planck Institute for Human and Cognitive Sciences, \\ Leipzig, Germany
}

\begin{abstract}
Introduction: Auditory verbal hallucinations (AVH) are a core symptom of psychotic disorders such as schizophrenia but are also reported in $10-15 \%$ of the general population. Impairments in selfvoice recognition are frequently reported in schizophrenia and associated with the severity of $\mathrm{AVH}$, particularly when the self-voice has a negative quality. However, whether self-voice processing is also affected in nonclinical voice hearers remains to be specified.

Methods: Thirty-five nonclinical participants varying in hallucination predisposition based on the Launay-Slade Hallucination Scale, listened to prerecorded words and vocalisations differing in identity (self/other) and emotional quality. In Experiment 1, participants indicated whether words were spoken in their own voice, another voice, or whether they were unsure (recognition task). They were also asked whether pairs of words/vocalisations were uttered by the same or by a different speaker (discrimination task). In Experiment 2, participants judged the emotional quality of the words/vocalisations. Results: In Experiment 1, hallucination predisposition affected voice discrimination and recognition, irrespective of stimulus valence. Hallucination predisposition did not affect the evaluation of the emotional valence of words/vocalisations (Experiment 2).

Conclusions: These findings suggest that nonclinical participants with high HP experience altered voice identity processing, whereas HP does not affect the perception of vocal emotion. Specific alterations in selfvoice perception in clinical and nonclinical voice hearers may establish a core feature of the psychosis continuum.
\end{abstract}

\section{ARTICLE HISTORY}

Received 27 August 2018

Accepted 13 May 2019

\section{KEYWORDS}

Hallucination predisposition; self; voice; discrimination; recognition

\section{Introduction}

Auditory verbal hallucinations (AVH; subjective perceptions of voices in the absence of a corresponding external voice-Woodruff, 2004) represent one of the cardinal symptoms of schizophrenia and are experienced by almost $70 \%$ of patients (Nayani \& David, 1996). Nonetheless, the experience of AVH is not exclusive to schizophrenia: AVH are also reported by $10-15 \%$ of the general population (Daalman et al., 2011; Larøi et al., 
2012; Nayani \& David, 1996) ${ }^{1}$. Even though many nonclinical voice hearers do not progress to full psychosis, some will (Johns \& Van Os, 2001).

Despite numerous attempts to explain the neurocognitive mechanisms of AVH, they remain one of the notoriously unexplained symptoms on the psychosis continuum. Phenomenological features of AVH suggest changes in mechanisms underlying human voice perception (Badcock \& Chhabra, 2013; reviewed in Conde, Gonçalves, \& Pinheiro, 2016). In approximately $78 \%$ of voice hearers there is a clear awareness of the identity of the hallucinated voice or voices (e.g., a family member or a past abuser-Corstens \& Longden, 2013). Most AVH have specific acoustic features such as volume and pitch: for example, they are typically heard at the same volume as spoken words (CuevasYust, 2014). Notwithstanding, distinct AVH subtypes have been proposed to account for the phenomenological diversity of hearing voices (e.g., "constant commanding and commenting AVH", "replay AVH", "own thought"-McCarthy-Jones, Thomas, et al., 2014; McCarthy-Jones, Trauer, et al., 2014).

Similarities in the neural mechanisms underpinning the perception of real and hallucinated voices have been noted (Barkus, Stirling, Hopkins, McKie, \& Lewis, 2007; Linden et al., 2011). Similarities were also noted in the cognitive (Allen, Freeman, Johns, \& McGuire, 2006; Brébion et al., 2016) and neural mechanisms (Diederen et al., 2012) of AVH in clinical and nonclinical voice hearers. For example, voice areas in the temporal cortex, which selectively respond to voices compared to nonvocal sounds (Belin, Fecteau, \& Bédard, 2004), are activated during spontaneous hallucinations both in psychotic and nonclinical voice hearers (Barkus et al., 2007; Diederen et al., 2012; Horga, Schatz, Abi-Dargham, \& Peterson, 2014; Linden et al., 2011; Sommer et al., 2008). These findings suggest a neural substrate specific to AVH rather than schizophrenia (Larøi et al., 2012). They are also considered to support the psychosis continuum hypothesis, according to which psychotic symptoms exist on a continuum in the general population (e.g., Badcock \& Chhabra, 2013; Van Os, Linscott, Myin-Germeys, Delespaul, \& Krabbendam, 2009). Studying hallucinatory experiences in nonclinical samples could help to unveil the neurocognitive mechanisms underlying $\mathrm{AVH}$, while avoiding confounding effects associated with medication and hospitalisation (Badcock \& Hugdahl, 2012).

\section{Voice identity perception in AVH}

When somebody speaks, the voice carries not only information about what is said (speech) but also about who speaks (e.g., age, gender, or emotional state). Identity, affect, and speech cues carried by the voice are processed in partially dissociated cortical regions (Belin, Bestelmeyer, Latinus, \& Watson, 2011; Belin et al., 2004). Dissociations between impaired processing of one type of voice information and preserved processing of the other types have been documented (e.g., phonagnosia-Garrido et al., 2009).

A robust body of evidence has shown that the mechanisms involved in the prediction and processing of self-voice feedback (when speaking or pressing a button that elicits a prerecorded self-generated voice) are altered in AVH (Allen et al., 2004, 2007, 2006; HeinksMaldonado et al., 2007; Pinheiro, Schwartze, \& Kotz, 2018). Behavioural studies reported increased errors in the recognition of self-voice feedback or prerecorded self-generated speech in AVH. Schizophrenia patients with AVH are more likely than both schizophrenia 
patients without hallucinations and healthy controls to misidentify prerecorded self-generated speech as produced by another person (Allen et al., 2004). A tendency to consider selfgenerated speech feedback as external was also found in at-risk mental state participants when speaking (Johns et al., 2010). Changes in self-generated voice processing are also shown in neuroimaging studies with psychotic patients. Activation in the right middle temporal gyrus (Kambeitz-Ilankovic et al., 2013) and the left superior temporal gyrus (Allen et al., 2007) did not differ for prerecorded self-generated and other voices in first-episode psychosis or chronic schizophrenia patients with AVH, respectively.

Nonetheless, it remains unclear whether altered self-voice processing is a marker of individuals with AVH even in the absence of psychosis. The few studies that probed how nonclinical voice hearers perceive voice identity have not consistently reported changes in bottom-up acoustic analysis of the voice (contrary to psychotic patients with $\mathrm{AVH}$ ) as voice identity discrimination of unfamiliar speakers was spared (Chhabra, Badcock, \& Maybery, 2013; Chhabra, Badcock, Maybery, \& Leung, 2014). Specifically, Chhabra and colleagues (2014) found that nonclinical participants with high vs. low hallucination predisposition (HP), quantified as the total score in the Launay-Slade Hallucination Scale (LSHS-Launay \& Slade, 1981), performed similarly in a voice discrimination task with unfamiliar voices. Nonetheless, this study did not report whether (self-)voice recognition (relying more strongly on higher-level cognitive processes, such as prior knowledge than voice discrimination) is also unaffected in nonclinical voice hearers.

\section{Emotional voice perception in AVH}

Hallucinated voices have a predominantly emotional quality (Baumeister, Sedgwick, Howes, \& Peters, 2017; Nayani \& David, 1996; Waters et al., 2012; Waters \& Fernyhough, 2017), often a threatening tone and derogatory and menacing content particularly in psychotic voice hearers (Nayani \& David, 1996).

Alterations in emotional voice processing have been associated with AVH severity (Alba-Ferrara, de Erausquin, Hirnstein, Weis, \& Hausmann, 2013; Rossell \& Boundy, 2005; Shea et al., 2007; Tseng et al., 2013). For example, even though schizophrenia patients are generally impaired in decoding emotion from speech with semantic content, only patients with AVH show deficits in recognising meaningless affective sounds (Rossell \& Boundy, 2005) or emotional prosody (Shea et al., 2007) compared to patients without $\mathrm{AVH}$ and healthy controls. Patients with $\mathrm{AVH}$ also displayed difficulties ignoring the emotional valence of the voice (Alba-Ferrara et al., 2013). Altered processing of vocal emotions has been reported in nonclinical voice hearers as well (Phillips \& Seidman, 2008).

Alterations in self-voice perception could be modulated by the emotional quality of the voice. Accordingly, a negativity bias was observed in self-other voice recognition tasks with psychotic participants: patients with AVH compared to healthy controls and non-hallucinating patients judged prerecorded self-generated negative speech (e.g., words such as "stupid") as "other" (Costafreda, Brébion, Allen, McGuire, \& Fu, 2008; Johns et al., 2001, 2010; Pinheiro, Rezaii, Rauber, \& Niznikiewicz, 2016). When listening to distorted feedback of their own voice, schizophrenia patients with AVH, but not healthy controls, perceived their own distorted voice as an unfamiliar voice when the spoken words had a negative content (e.g., Johns et al., 2001). What is 
unknown is whether self-voice perception in participants with high HP is modulated by emotion similarly to psychotic voice hearers.

\section{The role of stimulus type and task}

The mechanisms involved in self-voice perception could be modulated by the type of vocal stimulus as well as by task instructions. Prior studies have shown that both stimulus type (e.g., vocal sounds with [words] vs. without [vocalisations] semantic content) and attentional focus demanded by the task (e.g., attention directed to the voice or to a concurrent visual stimulus) affect self-other voice discrimination (Conde, Gonçalves, \& Pinheiro, 2015). Differences in the neurocognitive mechanisms subserving the processing of speech and nonverbal vocalisations have also been shown (e.g., Pell \& Kotz, 2011). For example, the differentiation of neutral and emotional cues occurred earlier for nonverbal vocalisations compared to speech prosody (Pell et al., 2015). Probing the role of stimulus type in self-voice perception is critical considering that AVH were associated with worse recognition of nonverbal emotional vocalisations (Rossell \& Boundy, 2005) or unintelligible emotional speech (Shea et al., 2007).

It is also worth noting that experimental tasks tapping into voice discrimination vs. voice recognition probe different levels of processing that might be dissociable (e.g., Kreiman \& Papcun, 1991; Van Lancker \& Kreiman, 1987; Van Lancker, Kreiman, \& Cummings, 1989). Whereas voice discrimination relies mostly on bottom-up processes decoding the acoustic features of the voice (i.e., on basic perceptual abilities), voice recognition involves the integration of low-level acoustic properties with prior knowledge about the speaker, thus merging bottom-up and top-down processes (Belin et al., 2011; Sohoglu, Peelle, Carlyon, \& Davis, 2012). Hence, discrimination is thought to precede recognition in traditional models of person recognition (Bruce \& Young, 1986; Burton, Bruce, \& Johnston, 1990). Schizophrenia patients present alterations in auditory feature perception that could contribute to changed voice discrimination as hallucinated voices may compete for auditory processing resources; however, these changes were not clearly moderated by AVH (Ford et al., 2012; Javitt, Shelley, \& Ritter, 2000; Schnakenberg Martin et al., 2018). Impaired self-voice recognition has been documented in schizophrenia patients (Allen et al., 2004, 2007; Ilankovic et al., 2011; Pinheiro et al., 2016), whereas preserved voice discrimination was observed in individuals with high HP (Chhabra et al., 2014). Nonetheless, whether hallucination proneness (measured via psychometric tools, such as self-report scales [e.g., LSHS]) in nonclinical participants is associated with altered self-voice recognition remains to be clarified. This would indicate that higher-level cognitive processes underpinning self-voice recognition might be a more sensitive marker of AVH.

\section{The current study and hypotheses}

An emerging theme from the findings reviewed above is that alterations in both identity (self-voice) and emotional (negative) voice perception may underlie the experience of "hearing voices" in psychotic patients. Whether similar alterations are present in nonclinical participants with high HP remains an open question. As emotional and identity cues are processed in partially dissociated cortical regions in voice perception (Belin et al., 
2011), an increase in HP could reveal altered voice identity rather than altered emotional voice processing or vice-versa. The current study probed whether and how HP in nonclinical participants reveals such effects.

$\mathrm{n}$ the first experiment, we examined how participants perceived their own voice in two tasks that tap into voice discrimination (are the two voices the same or different?) and voice recognition (have I heard my voice or the voice of somebody else?). In the two tasks, we probed whether self-voice perception is modulated by stimulus valence (positive $v s$. negative) and stimulus type (with [speech] vs. without [vocalisations] verbal content). Based on previous evidence, we hypothesised that HP would not affect self-other voice discrimination (e.g., Chhabra et al., 2014). However, we expected HP to modulate accuracy in self-voice recognition consistent with a psychosis continuum (e.g., Allen et al., 2004; Johns et al., 2001; Pinheiro et al., 2016). Specifically, lower recognition accuracy for self-voices with negative content would support the hypothesis that altered processing of both voice identity and emotion underlie AVH in nonclinical and psychotic participants (e.g., Johns et al., 2001; Pinheiro et al., 2016). Along the same line, we expected recognition accuracy to be decreased when the self-voice is devoid of semantic content, i.e. in response to vocalisations rather than words (as in psychotic patients-Rossell \& Boundy, 2005; Shea et al., 2007; Zarate, Tian, Woods, \& Poeppel, 2015).

In the second experiment, we examined whether the putative effects of HP on selfvoice processing are due to differences in the emotional evaluation of auditory signals. Participants were instructed to explicitly rate the emotional valence of words and vocalisations used in Experiment 1. We expected increased HP to be associated with more negative valence ratings of self-generated voices (e.g., Pinheiro et al., 2016). Similarities in the processing of self-generated voices in nonclinical participants with high $\mathrm{HP}$ and psychotic patients would support the psychosis continuum hypothesis (Diederen et al., 2012).

\section{Method}

\section{Participants}

Participants were recruited based on total scores of the Launay-Slade Hallucination ScaleRevised $^{2}$ (LSHS-Frank Larøi \& Van Der Linden, 2005; Portuguese adaptation by Castiajo \& Pinheiro, 2017; originally developed by Launay \& Slade, 1981). In stage 1, a total of 484 participants filled in an online version of the scale, using the Qualtrics platform. To encourage participation, a voucher was offered. Over a 12-month recruitment period, 37 participants from stage 1 , and who consented to be contacted for further research on voice processing, were interviewed in more detail about their experiences and clinical history. All participants (native speakers of European Portuguese) completed a thorough clinical assessment that established that, for those who reported AVH (and thus with higher scores on the scale), voices were unrelated to drug or alcohol abuse. This clinical assessment also established that participants did not have a psychiatric diagnosis or had received a psychiatric diagnosis in relation to voice hearing. This was based on a semi-structured interview that aimed to assess different aspects of the personal history of the participants, namely: developmental history (age of major milestones); major illnesses and medication; presence of traumatic events in the past; health family history; educational history. They 
Table 1. Linguistic properties of the words included in the experiment.

\begin{tabular}{lcccr}
\hline & \multicolumn{3}{c}{ Valence } \\
\cline { 2 - 4 } Linguistic properties & Neutral & Positive & Negative & $F, p^{\text {a }}$ \\
\hline Frequency per million $^{\text {b }}$ & $14.90(17.36)$ & $10.47(11.42)$ & $6.69(8.25)$ & $2.027, .141$ \\
Number of letters $_{\text {Number of syllables }}^{6.45(1.57)}$ & $8.05(2.24)$ & $7.35(2.68)$ & $2.634, .081$ \\
\hline & $3.10(0.91)$ & $3.60(1.10)$ & $3.20(1.15)$ & $1.251, .294$ \\
\hline
\end{tabular}

Note: Standard deviation shown in parentheses.

a One-way ANOVA; ${ }^{\text {b }}$ Values retrieved from the P-Pal web application (Soares et al., 2018).

were additionally assessed using the Brief Symptom Inventory (Canavarro, 1999), Schizotypal Personality Questionnaire (Raine, 1991) and PSYRATS (Telles-Correia et al., 2017). Two participants did not enrol in the subsequent experimental session as they reported a psychiatric diagnosis. Thirty-five participants, varying in their LSHS scores (total score: $M=23.17, S D=14.77$, range $=0-54$; auditory score: $M=3.40, S D=3.70$, range $=0-12$ ), accepted to participate in the experimental sessions $\left(M_{\text {age }}=26.74, S D_{\text {age }}=8.28,26\right.$ females).

All participants provided written consent and received a voucher for their participation in the study. The study was conducted in accordance with the Declaration of Helsinki and was approved by the local Ethics Committee. ${ }^{3}$

\section{Stimuli}

Stimuli were pre-recorded words (Table 1) and vocalisations (self-generated voice condition [SGV]; see Supplementary Material for further details).

For the other voice (OV) condition, the same words and vocalisations were recorded by a male (age $=22$ years) or female (age $=20$ years) native speaker of European Portuguese and unknown to the participants (for a male participant, a male control voice was used; for a female participant, a female control voice was used), using the same procedure for the SGV condition. The same "voice-model" was used during voice recordings for the SGV and $\mathrm{OV}$ conditions.

After the voice recording session, each word and vocalisation was segmented using Praat software (Boersma, P., Weenink, 2013). SGV vocalisations were selected to match the duration of OV vocalisations. Following prior studies (Pinheiro et al., 2017, 2016),

Table 2. Acoustic properties of words and vocalisations in the SGV and OV conditions.

\begin{tabular}{|c|c|c|c|c|c|}
\hline Stimulus type & Valence & Acoustic property & SGV & OV-Male & OV-Female \\
\hline \multirow[t]{9}{*}{ Words } & \multirow[t]{3}{*}{ Neutral } & DUR (s) & 1.19 & 1.03 & 1.16 \\
\hline & & $\mathrm{FO}_{\mathrm{M}}(\mathrm{Hz})$ & 162.49 & 110.18 & 181.96 \\
\hline & & $\mathrm{INT}_{\mathrm{M}}(\mathrm{dB})$ & 70 & 70 & 70 \\
\hline & \multirow[t]{3}{*}{ Positive } & DUR (s) & 1.35 & 1.21 & 1.38 \\
\hline & & $\mathrm{FO}_{\mathrm{M}}(\mathrm{Hz})$ & 169.79 & 112.91 & 177.51 \\
\hline & & $\mathrm{INT}_{\mathrm{M}}(\mathrm{dB})$ & 70 & 70 & 70 \\
\hline & \multirow{3}{*}{ Negative } & DUR (s) & 1.23 & 1.02 & 1.18 \\
\hline & & $\mathrm{FO}_{\mathrm{M}}(\mathrm{Hz})$ & 162.60 & 110.53 & 186.37 \\
\hline & & $\mathrm{INT}_{\mathrm{M}}(\mathrm{dB})$ & 70 & 70 & 70 \\
\hline \multirow{6}{*}{ Vocalisations } & \multirow{3}{*}{ Positive } & DUR (s) & 1.18 & 1.04 & 1.24 \\
\hline & & $\mathrm{FO}_{\mathrm{M}}(\mathrm{Hz})$ & 218.16 & 139.08 & 211.77 \\
\hline & & $\mathrm{INT}_{\mathrm{M}}(\mathrm{dB})$ & 70 & 70 & 70 \\
\hline & \multirow[t]{3}{*}{ Negative } & DUR (s) & 0.95 & 0.91 & 0.97 \\
\hline & & $\mathrm{FO}_{\mathrm{M}}(\mathrm{Hz})$ & 222.51 & 139.47 & 249.25 \\
\hline & & $\mathrm{INT}_{\mathrm{M}}(\mathrm{dB})$ & 70 & 70 & 70 \\
\hline
\end{tabular}

Note: SGV, self-generated voice; OV, other voice; DUR, duration; $\mathrm{FO}_{\mathrm{M}}$, mean F0; $\mathrm{INT}_{\mathrm{M}}$, mean intensity. 
voice stimuli were normalised according to peak amplitude by means of a Praat script (70 dB). Mean pitch (fundamental frequency [F0] measured in $\mathrm{Hz}$ ), intensity (measured in $\mathrm{dB}$ ) and duration (measured in $\mathrm{ms}$ ) were calculated for each condition (Table 2).

\section{Procedure}

The experimental tasks took place in a sound-attenuated chamber. Stimulus presentation and timing were controlled using E-Prime 2.0 software (Psychology Software Tools).

\section{Experiment 1: focus on voice identity}

In same-different speaker discrimination tasks, participants listened to 180 word pairs of and 120 vocalisation pairs. They were asked to decide whether they had listened to the same or to different voices by pressing a corresponding button on the keyboard. In the case of words, 60 SGV/SGV, $60 \mathrm{OV} / \mathrm{OV}$, and 60 SGV/OV pairs (differing in valence: 60 positive, 60 neutral, 60 negative pairs) were presented. In the case of vocalisations, $40 \mathrm{SGV} / \mathrm{SGV}, 40 \mathrm{OV} / \mathrm{OV}$, and 40 SGV/OV pairs (differing in valence: 60 positive, 60 negative pairs) were presented.

In the voice recognition tasks, participants listened to 120 words (60 SGV and $60 \mathrm{OV}$ words differing in valence: 40 neutral, 40 positive and 40 negative) and 80 nonverbal vocalisations (40 SGV and $40 \mathrm{OV}$ differing in valence: 40 positive and 40 negative). They were asked to decide if they had listened to their own voice, to another voice, or whether they were unsure, via a button press on the keyboard. The availability of an "unsure" response encouraged responses with some degree of confidence in the identification response instead of a forced choice between "self" and "other" (Allen et al., 2004; Pinheiro et al., 2016). This task was identical to a previous task used in a sample of persons with schizophrenia (Pinheiro et al., 2016). Stimuli were presented in a randomised manner.

Before voice onset, a fixation cross was presented centrally on the screen for 1500 milliseconds (ms), and remained during sound presentation (Figure 2). Then, a question mark signalled the beginning of the response time (6 seconds). A $1000 \mathrm{~ms}$ interval preceded the next trial. In each task, participants were given five practice trials with response feedback, as well as a short break every 20 trials (with a duration of approximately 1 minute).

\section{Experiment 2: focus on voice emotion}

Participants were instructed to assess the emotional valence of each of the 60 words and 80 vocalisations they had listened to. Each stimulus was presented centrally on the screen, in a randomised manner, and participants rated its valence on a 9-point Likert scale ( $1=$ extremely negative; $9=$ extremely positive). Before the stimulus onset, a fixation cross was presented in the centre of the screen for $1500 \mathrm{~ms}$ where it remained during the sound presentation. Then, the question "How would you rate this stimulus?" was presented, accompanied by a 9-point Likert scale ( $1=$ extremely negative; $9=$ extremely positive). There was no time limit for the response. Participants were provided a short break every 20 trials (with a duration of approximately 1 minute).

\section{Statistical analyses}

Unaggregated, trial-level data from both experiments were analysed with mixed linear models using the lmer4 (Bates, Maechler, Bolker, \& Walker, 2015) and lmerTest 
(Kuznetsova, Brockhoff, \& Christensen, 2016) packages in the $\mathrm{R}$ environment (R3.4.3. GUI 1.70) used to estimate fixed and random coefficients. In contrast to the more traditional repeated-measures ANOVA analysis, LMER allows controlling for the variance associated with random factors such as random effects for participants in behavioural measures (Kuznetsova et al., 2016). Participants' responses were included as an outcome measure; participants were included as random effects, whereas stimulus type (words; vocalisations), voice identity (SGV; OV), valence (neutral, positive, negativewords; positive, negative-vocalisations) and $\mathrm{HP}$ ( $\left.\mathrm{LSHS}_{\text {Total }}\right)$ were included as fixed effects.

Power estimates: The literature is still scarce considering the computation of power estimates for multilevel models since several factors may impact upon this estimation (e.g., number of levels, type of design). Simulation studies revealed that parameter estimates are not reliable and Type I error increases only when level-2 sample size is below 30, with an increased bias for random slope models, but not for random intercept models (e.g., McNeish \& Stapleton, 2016; Meuleman \& Billiet, 2009). The number of clusters and their size do not seem to have an effect on fixed estimates and level-1 variance estimates (McNeish \& Stapleton, 2016). Post-experiment power calculations may be limited (Hoenig \& Heisey, 2001). Instead, confidence intervals (provided in the next section), as well as appropriate choices of null hypotheses, may provide more useful information (Hoenig \& Heisey, 2001).

\section{Results}

\section{Experiment 1: focus on voice identity}

\section{Accuracy}

Voice discrimination. The model including the predictors was strongly preferred based on Akaike Information Criterion (AIC) compared to the null model (6389.500 for the complete model and 13888.200 for the null model; $\left.\chi^{2}=7526.700, d f=14, p<.001\right)$. Stimulus type, identity and valence modulated voice discrimination (Figure 1 and Table 3 ). Vocalisations were associated with less accurate discrimination compared to words (effect of stimulus type: $\beta=-2.034, \mathrm{SE}=0.134, z=-15.164, p<.001 ; 95 \% \mathrm{CI}:[-2.297,-1.771])$. Congruent $\mathrm{OV}$ word pairs were associated with lower accuracy compared to congruent SGV word pairs (effect of identity: $\beta=-0.663, \mathrm{SE}=0.260, z=-2.553, p=.011 ; 95 \% \mathrm{CI}$ : $[-0.154,1.172])$. Further, negative word pairs were associated with lower accuracy compared to positive word pairs (effect of valence: $\beta=-0.498$, SE $=0.109, z=-4.579, p<.001$; 95\% CI: $[-0.711,-0.285])$. An interaction effect between HP and voice identity on discrimination performance $(\beta=0.028, \mathrm{SE}=0.005, z=5.311, p<.05,95 \% \mathrm{CI}:[0.018$, $0.038]$ ) revealed that an increase in HP was associated with an increased tendency to consider pairs of dissimilar voices (i.e., pairs of self $v s$. non-self stimuli) as "same". Based on the analysis of simple slopes, accuracy in voice discrimination was significantly decreased if $\mathrm{LSHS}_{\text {Total }}>30$.

Voice recognition. To investigate the potential impact of acoustic differences between SGV and OV recognition, voice mean F0 was added as a fixed effect to the model. The model including the predictors was strongly preferred based on AIC compared to the 


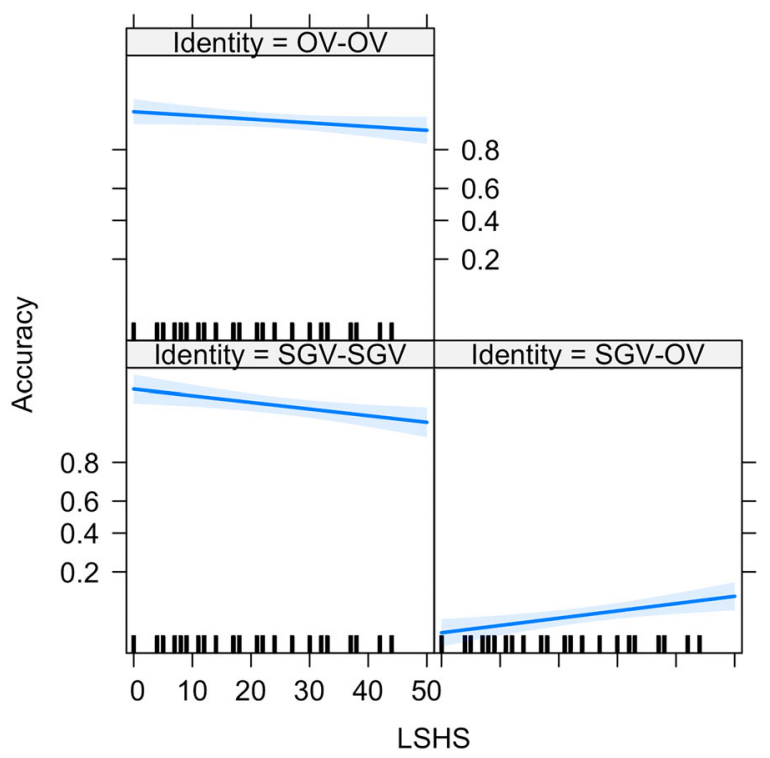

Figure 1. Voice discrimination as a function of hallucination predisposition. Note: SGV, self-generated voice; OV, other voice. Reference level of the response = "same".

null model ( 881.760 for the complete model and 1301.870 for the null model; $\chi^{2}=440.110$, $d f=10, p<.001)$.

Stimulus type modulated voice recognition: vocalisations were associated with less accurate recognition compared to words $(\beta=-0.133, \mathrm{SE}=0.010, t=-13.649, p<.001$, $95 \%$ CI: $[-0.152,-0.114])$. Voice recognition was also modulated by valence: accuracy was reduced for negative compared to positive stimuli $(\beta=-0.035, \mathrm{SE}=0.010, t=$ $-3.651, p<.001,95 \% \mathrm{CI}$ : $[-0.054,-0.016])$. An interaction effect between identity and valence indicated lower accuracy in self- ( $v s$. other) voice recognition when the stimulus was negative $(\beta=0.039, \mathrm{SE}=0.014, t=2.868, p=.004,95 \% \mathrm{CI}$ : $[0.012,0.066])$.

Consistent with our hypothesis, HP affected recognition accuracy. An interaction effect between $\mathrm{HP}$ and voice identity $(\beta=-0.001, \mathrm{SE}=0.000, t=-3.035, p=.002,95 \% \mathrm{CI}$ : $[-0.002,0.000])$ revealed that an increase in HP was associated with decreased accuracy in self-voice recognition (Figure 2 and Table 4). Based on the analysis of simple slopes,

Table 3. Accuracy in voice discrimination (Experiment 1).

\begin{tabular}{llr}
\hline & & Accuracy \\
\cline { 2 - 3 } Factor & $M$ & SD \\
\hline Stimulus type & & \\
Words & 0.96 & 0.20 \\
Vocalisation & 0.79 & 0.41 \\
Identity & & \\
SGV-SGV & 0.92 & 0.27 \\
SGV-OV & 0.90 & 0.30 \\
OV-OV & 0.85 & 0.36 \\
Emotion & & \\
Positive & 0.89 & 0.31 \\
Negative & 0.85 & 0.35 \\
Neutral & 0.96 & 0.21 \\
\hline
\end{tabular}

Note: SGV, self-generated voice; OV, other voice. 


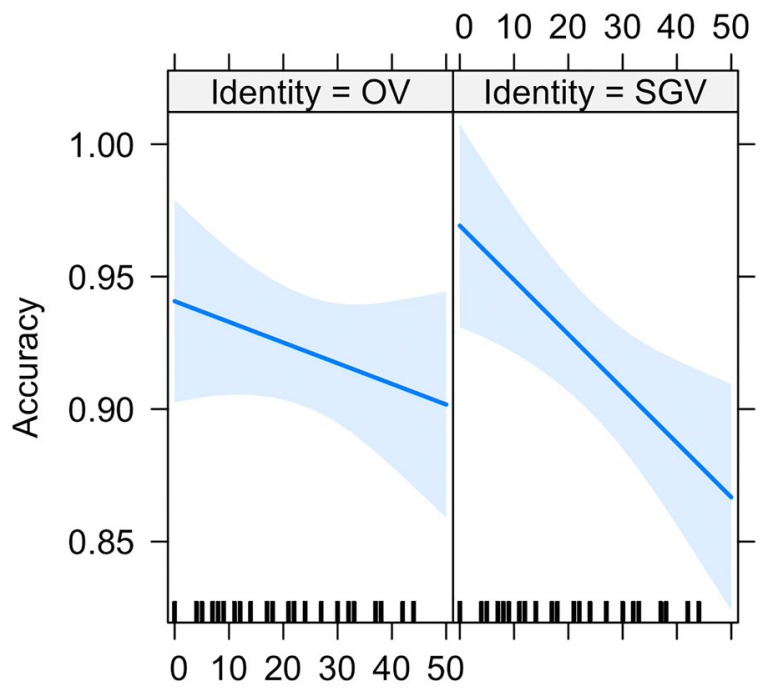

LSHS

Figure 2. Voice recognition as a function of hallucination predisposition. Note: SGV, self-generated voice; OV, other voice.

accuracy in self-voice recognition was expected to be significantly decreased if $\mathrm{LSHS}_{\text {Total }}>$ 30.

The number of "unsure" responses (reference level $=$ "unsure" responses $v s$. "self" and "other" responses) was modulated by stimulus type only ( $\beta=1.876, \mathrm{SE}=0.259, t=7.236$, $p<.001,95 \%$ CI: $[1.368,2.384]$; Supplementary Table 4): participants were less certain they heard their own voice or the voice of another person when the stimulus was a vocalisation compared to a word.

\section{Experiment 2: focus on voice emotion}

Ratings of words' valence: Negative words elicited lower valence ratings than neutral words $(\beta=-2.779, \mathrm{SE}=0.117, t=-23.704, p<.001,95 \% \mathrm{CI}:[-3.008,-2.549])$; positive words received higher valence ratings than neutral words $(\beta=2.853, \mathrm{SE}=0.117, t=24.338$,

Table 4. Accuracy in voice recognition (Experiment 1).

\begin{tabular}{llr}
\hline Factor & & Accuracy \\
\cline { 2 - 3 } & $M$ & SD \\
\hline Stimulus Type & & \\
Words & 0.97 & 0.16 \\
Vocalisation & 0.85 & 0.36 \\
Identity & & \\
SGV & 0.92 & 0.27 \\
OV & 0.92 & 0.27 \\
Emotion & & \\
Positive & 0.91 & 0.28 \\
Negative & 0.90 & 0.30 \\
Neutral & 0.98 & 0.16 \\
\hline
\end{tabular}

Note: SGV, self-generated voice; OV, other voice. 
$p<.001 ; 95 \%$ CI: [2.623, 3.083]; Table 5). HP did not affect explicit ratings of the emotional quality of words $(\beta=-0.004, \mathrm{SE}=0.0033, t=-1.266, p=.208)$.

Ratings of vocalisations' valence: Negative vocalisations were rated as less positive than positive vocalisations $(\beta=-4.130, \mathrm{SE}=0.182, t=-22.645, p<.001,95 \% \mathrm{CI}:[-4.487$, $-3.773])$; OV vocalisations were rated as less positive than SGV vocalisations $(\beta=$ $-0.636, \mathrm{SE}=0.182, t=-3.486, p<.001$; 95\% CI: $[-0.993,-0.278]$; Table 5$)$. The effects of identity and valence interacted showing that $\mathrm{OV}$ negative vocalisations were rated as less negative than SGV negative vocalisations $(\beta=0.916, \mathrm{SE}=0.258, t=3.550, p<.001$, 95\% CI: $[0.410,1.421])$. HP also did not affect explicit ratings of the emotional quality of vocalisations $(\beta=0.002, \mathrm{SE}=0.004, t=-0.423, p=.673)$.

\section{Discussion}

The current study examined whether HP in nonclinical participants modulates self-voice processing differently in discrimination and recognition tasks and tested the contributions of valence and stimulus type in both tasks (Experiment 1). Further, the effects of HP on the explicit evaluation of the emotional quality of voices were examined (Experiment 2). Experiment 1 revealed differences in voice processing as a function of task type. Both voice recognition and discrimination were changed in participants with increased HP. Irrespective of stimulus type (with or without semantic content) and valence (positive or negative), participants were less accurate at recognising their self-generated voice as "self" the more prone they were to hallucinations. Increased HP was also associated with an increased tendency to consider that pairs of different voices (self and other) corresponded to the same speaker. Experiment 2 confirmed that the evaluation of the emotional quality of voices was not modulated by HP.

\section{The role of hallucination predisposition in self-other voice discrimination}

Overall, discrimination was affected by stimulus type, voice identity, and the emotional quality (valence) of the voice: judgments of acoustic similarity were improved when participants listened to words rather than vocalisations and specifically when positive content words were uttered by the participant. The results of the discrimination task (involving a simple differentiation of self and other voices) agree with a noted processing advantage associated with self-generated voices (e.g., Conde et al., 2015). One's own voice represents a more familiar signal, which is more easily matched with speaker-specific stored representations (Belin et al., 2011; Blank, 2002; Nakamura et al., 2001). The voice of an unknown speaker is a less familiar stimulus that is processed in a bottom-up manner and compared to averaged prototypical voice templates (Andics, McQueen, \& Petersson, 2013; Andics

Table 5. Mean valence ratings of words and vocalisations (Experiment 2).

\begin{tabular}{lccr}
\hline & \multicolumn{3}{c}{ Valence } \\
\cline { 2 - 4 } Stimulus type & Neutral & Positive & Negative \\
\hline 1. Words & $5.04(0.32)$ & $7.89(0.45)$ & $2.26(0.67)$ \\
2. Vocalisations-SGV & - & $7.03(0.72)$ & $2.90(0.93)$ \\
3. Vocalisations-OV & - & $6.39(0.69)$ & $3.18(0.74)$ \\
\hline
\end{tabular}

Note: Standard deviation shown in parentheses. SGV, self-generated voice; OV, other voice. 
et al., 2010; Belin et al., 2011). Voice familiarity has been reported to affect speaker discrimination performance (Lavan, Scott, \& McGettigan, 2016). Similarly, the current study suggests that familiarity (one's own voice) increases discrimination performance.

A positivity bias (reflected in a facilitated processing of positive stimuli related to the self) has been consistently reported in self-voice perception research (Chen et al., 2014; Fields \& Kuperberg, 2012; Watson, Dritschel, Obonsawin, \& Jentzsch, 2007). For example, when judging the self-referential content of positive and negative words, participants were faster in judging positive words uttered by themselves than by an unknown speaker (Watson et al., 2007). Moreover, word discrimination was easier than vocalisation discrimination and agrees with prior studies that showed that the processing of speech (with verbal content) compared to vocalisations (no verbal content) is subserved by different neurocognitive mechanisms (Belin et al., 2004; Conde et al., 2015; Pell et al., 2015). Contrary to our hypothesis and prior evidence (Chhabra et al., 2014), we observed that discrimination was affected by HP. However, this finding agrees with reports of altered voice discrimination in schizophrenia patients, namely the ability to use formant dispersion to discriminate voices (Chhabra, Badcock, Maybery, \& Leung, 2012). AVH have been associated with alterations in the auditory cortex (Mørch-Johnsen et al., 2017), which may be reflected in N1 (Pinheiro, Schwartze, \& Kotz, 2018) or P50 (Thoma et al., 2017) amplitude changes. Changes in self-other voice discrimination as a function of increased HP may involve changes in basic perceptual abilities (e.g., Schnakenberg Martin et al., 2018) that are critical for identity perception.

\section{The role of hallucination predisposition in self-other voice recognition}

Whereas differences in identity or emotion did not affect voice recognition, recognition accuracy was increased for words compared to vocalisations, following the same pattern as discrimination accuracy. Voice recognition was improved as a function of available information (acoustic, phonological, semantic), i.e. speech was associated with increased accuracy compared to nonverbal vocalisations (the condition with the least amount of phonological information) (Zarate et al., 2015). Speech content, which is absent in nonverbal vocalisations, was found to be critical in person recognition (Lavan et al., 2016). Notwithstanding, even though self-other recognition of nonverbal vocalisations was more difficult than self-other recognition in speech, accuracy was still above chance (Zarate et al., 2015), a finding replicated in the current study. This implies that purely acoustic or paralinguistic features of the voice may be sufficient for extracting identityrelated information (Zarate et al., 2015).

The voice identity recognition task confirmed that self-voice perception is changed in nonclinical voice hearers. Specifically, increased HP changed participants' capacity to recognise their own voice, irrespective of stimulus type: the tendency to consider one's own voice as "other" was increased for both words and vocalisations, and more pronouncedly when the LSHS score was above 30 . Contrary to our hypothesis, we did not observe that participants with increased HP were particularly prone to misrecognise their own voice when its valence was negative. The finding that voice identity recognition (self $v s$. other) was not biased by emotional factors in nonclinical AVH differs from prior studies with AVH psychotic patients (Allen et al., 2004; Johns et al., 2001; Pinheiro 
et al., 2016): these studies showed that self-voice recognition was specifically affected in the case of negative stimuli.

\section{The role of hallucination predisposition in emotional voice evaluation}

Critically, self-voice processing differences as a function of HP were not associated with differences in the emotional evaluation of the voice (Experiment 2). That is, when participants' attention was focused on the emotional quality of the voice, those with higher HP evaluated words and vocalisations similarly to those with lower HP. Phenomenological differences between clinical and nonclinical voice hearers have been attributed to differences in how voices are appraised (Garety, Kuipers, Fowler, Freeman, \& Bebbington, 2001; Morrison, 2001), i.e. in a more negative way by clinical voice hearers. This may have accounted for by the lack of differences in the explicit valence evaluation in the current study. The finding that increased HP is associated with altered voice identity processing, but preserved emotional voice evaluation, provides additional support for a partial segregation of emotion and identity in voice perception (Belin et al., 2004).

\section{Implications}

Evidence for the psychosis continuum hypothesis has been inconsistent, with studies showing both similarities and differences in the mechanisms underlying AVH in clinical and nonclinical participants. We provide new evidence suggesting that altered self-voice discrimination and recognition represents a predisposing factor to hallucinatory experiences even in non-psychotic persons (see Alba-Ferrara, Weis, Damjanovic, Rowett, \& Hausmann, 2012; Mou et al., 2013 for studies with schizophrenia patients). The current findings provide partial support for continuum models of psychosis (e.g., Badcock \& Hugdahl, 2012; Van Os et al., 2009). Besides sensory-based operations (e.g., using pitch information for speakers' differentiation), higher-order cognitive processes such as perceptual expectations (Waters et al., 2012) or enhanced selective attention to non-familiar acoustic cues (Pinheiro et al., 2017) are critical in person recognition (Blank, Wieland, \& von Kriegstein, 2014). It is plausible that an interaction between bottom-up and top-down processes account for altered self-voice perception in AVH. Considering the low unstandardised beta values in the current study, these processes deserve further investigation in larger samples.

Differences between psychotic and non-psychotic participants may reflect changes in voice perception along the psychosis continuum: transition to psychosis may involve gradual changes in other voice dimensions (e.g., affect).

\section{Conclusions}

The findings of the current study indicate that hallucination predisposition affects both voice recognition and discrimination capacities. Contrary to psychotic patients with $\mathrm{AVH}$, alterations in self-voice recognition in nonclinical participants did not depend on the emotional quality of the voice or stimulus type. Further, explicit evaluation of the emotional quality of the voice was unimpaired. Specific alterations in voice identity perception may establish a core feature of the psychosis continuum. 


\section{Notes}

1. Approximately six percent (6.2\%) of non-psychotic individuals with frequent AVH convert to psychosis in a five-years follow-up (Daalman, Diederen, Hoekema, van Lutterveld, \& Sommer, 2016).

2. The total score ranges between 0 and 64 , with higher scores indicating higher HP.

3. Ethics Committee of Faculdade de Psicologia-Universidade de Lisboa, Lisbon (Portugal).

\section{Acknowledgments}

The authors gratefully acknowledge all the participants who collaborated in the study.

\section{Disclosure statement}

No potential conflict of interest was reported by the authors.

\section{Funding}

This work was supported by the Fundação para a Ciência e a Tecnologia [FCT; grant number PTDC/MHC-PCN/0101/2014] and BIAL Foundation (Fundação Bial) [grant number BIAL 238/ 16] awarded to APP and SAK.

\section{Ethical standards}

The authors assert that all procedures contributing to this work comply with the ethical standards of the relevant national and institutional committees on human experimentation and with the Helsinki Declaration of 1975, as revised in 2008.

\section{ORCID}

Ana P. Pinheiro (D) http://orcid.org/0000-0002-7981-3682

Magda S. Roberto (D) http://orcid.org/0000-0003-4127-561X

\section{References}

Alba-Ferrara, L., de Erausquin, G. A., Hirnstein, M., Weis, S., \& Hausmann, M. (2013). Emotional prosody modulates attention in schizophrenia patients with hallucinations. Frontiers in Human Neuroscience, 7, 59. doi:10.3389/fnhum.2013.00059

Alba-Ferrara, L., Weis, S., Damjanovic, L., Rowett, M., \& Hausmann, M. (2012). Voice Identity Recognition Failure in Patients With Schizophrenia. Journal of Nervous and Mental Disease, 200(9), 784-790. doi:10.1097/NMD.0b013e318266f

Allen, P., Amaro, E., Fu, C. H. Y., Williams, S. C. R., Brammer, M. J., Johns, L. C., \& McGuire, P. K. (2007). Neural correlates of the misattribution of speech in schizophrenia. British Journal of Psychiatry, 190, 162-169. doi:10.1192/bjp.bp.106.025700

Allen, P., Freeman, D., Johns, L., \& McGuire, P. (2006). Misattribution of self-generated speech in relation to hallucinatory proneness and delusional ideation in healthy volunteers. Schizophrenia Research, 84(2-3), 281-288. doi:10.1016/j.schres.2006.01.021

Allen, P., Johns, L. C., Fu, C. H. Y., Broome, M. R., Vythelingum, G. N., \& McGuire, P. K. (2004). Misattribution of external speech in patients with hallucinations and delusions. Schizophrenia Research, 69(2-3), 277-287. doi:10.1016/j.schres.2003.09.008 
Andics, A., McQueen, J. M., \& Petersson, K. M. (2013). Mean-based neural coding of voices. NeuroImage, 79, 351-360. doi:10.1016/j.neuroimage.2013.05.002

Andics, A., McQueen, J. M., Petersson, K. M., Gál, V., Rudas, G., \& Vidnyánszky, Z. (2010). Neural mechanisms for voice recognition. NeuroImage, 52(4), 1528-1540. doi:10.1016/j.neuroimage. 2010.05.048

Badcock, J. C., \& Chhabra, S. (2013). Voices to reckon with: perceptions of voice identity in clinical and non-clinical voice hearers. Frontiers in Human Neuroscience, 7, 114. doi:10.3389/fnhum. 2013.00114

Badcock, J. C., \& Hugdahl, K. (2012). Cognitive mechanisms of auditory verbal hallucinations in psychotic and non-psychotic groups. Neuroscience and Biobehavioral Reviews, 36(1), 431-438. doi:10.1016/j.neubiorev.2011.07.010

Barkus, E., Stirling, J., Hopkins, R., McKie, S., \& Lewis, S. (2007). Cognitive and neural processes in non-clinical auditory hallucinations. British Journal of Psychiatry, 191, s76-81. doi:10.1192/bjp. 191.51.s76

Bates, D., Maechler, M., Bolker, B., \& Walker, S. (2015). lme4: linear mixed-effects models using Eigen and S4. Journal of Statistical Software, 67, 1-48. doi:10.18637/jss.v067.i01

Baumeister, D., Sedgwick, O., Howes, O., \& Peters, E. (2017). Auditory verbal hallucinations and continuum models of psychosis: A systematic review of the healthy voice-hearer literature. Clinical Psychology Review, 51, 125-141. doi:10.1016/j.cpr.2016.10.010

Belin, P., Bestelmeyer, P. E. G., Latinus, M., \& Watson, R. (2011). Understanding Voice Perception. British Journal of Psychology, 102(4), 711-725. doi:10.1111/j.2044-8295.2011.02041.x

Belin, P., Fecteau, S., \& Bédard, C. (2004). Thinking the voice: Neural correlates of voice perception. Trends in Cognitive Sciences, 8(3), 129-135. doi:10.1016/j.tics.2004.01.008

Blank, S. C. (2002). Speech production: Wernicke, Broca and beyond. Brain, 125(8), 1829-1838. doi:10.1093/brain/awf191

Blank, H., Wieland, N., \& von Kriegstein, K. (2014). Person recognition and the brain: Merging evidence from patients and healthy individuals. Neuroscience and Biobehavioral Reviews, 47, 717734. doi:10.1016/j.neubiorev.2014.10.022

Boersma, P., \& Weenink, D. (2013). Praat: Doing phonetics by computer [Computer program]. Version 5.3.53. Retrieved from http://www.praat.org/.

Brébion, G., Stephan-Otto, C., Ochoa, S., Roca, M., Nieto, L., \& Usall, J. (2016). Impaired self-monitoring of inner speech in schizophrenia patients with verbal hallucinations and in non-clinical individuals prone to hallucinations. Frontiers in Psychology, 7, 1381. doi:10.3389/fpsyg.2016. 01381

Bruce, V., \& Young, A. (1986). Understanding face recognition. British Journal of Psychology, 77(3), 305-327. doi:10.1111/j.2044-8295.1986.tb02199.x

Burton, A. M., Bruce, V., \& Johnston, R. A. (1990). Understanding face recognition with an interactive activation model. British Journal of Psychology, 81(3), 361-380. doi:10.1111/j.2044-8295. 1990.tb02367.x

Canavarro, M. C. (1999). Inventário de Sintomas Psicopatológicos [Brief Symptoms Inventory]: BSI. In L. S. A. M. R. Simões \& M. Gonçalves (Eds.), Testes e provas psicológicas em Portugal [Psychological Tests in Portugal] (Vol. II, pp. 87-109). Braga: SHO/APPORT.

Castiajo, P., \& Pinheiro, A. P. (2017). On "hearing" voices and "seeing" things: Probing hallucination predisposition in a Portuguese nonclinical sample with the Launay-Slade Hallucination Scale-revised. Frontiers in Psychology, 8, 1138. doi:10.3389/fpsyg.2017.01138

Chen, Y., Zhong, Y., Zhou, H., Zhang, S., Tan, Q., \& Fan, W. (2014). Evidence for implicit self-positivity bias: an event-related brain potential study. Experimental Brain Research, 232, 985-994. doi:10.1007/s00221-013-3810-z

Chhabra, S., Badcock, J. C., \& Maybery, M. T. (2013). Memory binding in clinical and non-clinical psychotic experiences: how does the continuum model fare? Cognitive Neuropsychiatry, 18(4), 304-325. doi:10.1080/13546805.2012.709183

Chhabra, S., Badcock, J. C., Maybery, M. T., \& Leung, D. (2012). Voice identity discrimination in schizophrenia. Neuropsychologia, 50(12), 2730-2735. doi:10.1016/j.neuropsychologia.2012.08. 006 
Chhabra, S., Badcock, J. C., Maybery, M. T., \& Leung, D. (2014). Voice identity discrimination and hallucination-proneness in healthy young adults: a further challenge to the continuum model of psychosis? Cognitive Neuropsychiatry, 19(4), 305-18. doi:10.1080/13546805.2013.865512

Conde, T., Gonçalves, Ó. F., \& Pinheiro, A. P. (2015). The effects of stimulus complexity on the preattentive processing of self-generated and nonself voices: An ERP study. Cognitive, Affective, \& Behavioral Neuroscience, 16, 106-123.

Conde, T., Gonçalves, O. F., \& Pinheiro, A. P. (2016). A Cognitive Neuroscience view of voice processing abnormalities in schizophrenia: A window into auditory verbal hallucinations? Harvard Review of Psychiatry, 24(2), 148-163. doi:10.1097/HRP.0000000000000082

Corstens, D., \& Longden, E. (2013). The origins of voices: Links between life history and voice hearing in a survey of 100 cases. Psychosis, 5(3), 270-285. doi:10.1080/17522439.2013.816337

Costafreda, S. G., Brébion, G., Allen, P., McGuire, P. K., \& Fu, C. H. Y. (2008). Affective modulation of external misattribution bias in source monitoring in schizophrenia. Psychological Medicine, 38 (6), 821-824. doi:10.1017/S0033291708003243

Cuevas-Yust, C. (2014). Do thoughts have sound? Differences between thoughts and auditory hallucinations in schizophrenia. Spanish Journal of Psychology, 17(2), E27. doi:10.1017/sjp.2014.29

Daalman, K., Boks, M. P. M., Diederen, K. M. J., De Weijer, A. D., Blom, J. D., Kahn, R. S., \& Sommer, I. E. C. (2011). The same or different? A phenomenological comparison of auditory verbal hallucinations in healthy and psychotic individuals. Journal of Clinical Psychiatry, 72 (3), 320-325. doi:10.4088/JCP.09m05797yel

Daalman, K., Diederen, K. M. J., Hoekema, L., van Lutterveld, R., \& Sommer, I. E. C. (2016). Five year follow-up of non-psychotic adults with frequent auditory verbal hallucinations: are they still healthy? Psychological Medicine, 46(9), 1897-1907. doi:10.1017/S0033291716000386

Diederen, K. M. J., Daalman, K., De Weijer, A. D., Neggers, S. F. W., Van Gastel, W., Blom, J. D., ... Sommer, I. E. C. (2012). Auditory hallucinations elicit similar brain activation in psychotic and nonpsychotic individuals. Schizophrenia Bulletin, 38(5), 1074-1082. doi:10.1093/schbul/sbr033

Fields, E. C., \& Kuperberg, G. R. (2012). It's All About You: An ERP Study of Emotion and SelfRelevance in Discourse. NeuroImage, 62(1), 562-574. doi:10.1016/j.neuroimage.2012.05.003

Ford, J. M., Dierks, T., Fisher, D. J., Herrmann, C. S., Hubl, D., Kindler, J., ... Van Lutterveld, R. (2012). Neurophysiological studies of auditory verbal hallucinations. Schizophrenia Bulletin, 38(4), 715-723. doi:10.1093/schbul/sbs009

Garety, P. A., Kuipers, E., Fowler, D., Freeman, D., \& Bebbington, P. E. (2001). A cognitive model of the positive symptoms of psychosis. Psychological Medicine, 31(2), 189-195. doi:10.1017/ S0033291701003312

Garrido, L., Eisner, F., McGettigan, C., Stewart, L., Sauter, D., Hanley, J. R., ... Duchaine, B. (2009). Developmental phonagnosia: A selective deficit of vocal identity recognition. Neuropsychologia, 47(1), 123-131. doi:10.1016/j.neuropsychologia.2008.08.003

Heinks-Maldonado, T. H., Mathalon, D. H., Houde, J. F., Gray, M., Faustman, W. O., \& Ford, J. M. (2007). Relationship of imprecise corollary discharge in schizophrenia to auditory hallucinations. Archives of General Psychiatry, 64(3), 286-296. doi:10.1001/archpsyc.64.3.286

Hoenig, J. M., \& Heisey, D. M. (2001). The abuse of power: The pervasive fallacy of power calculations for data analysis. American Statistician, 55(1), 19-24. doi:10.1198/000313001300339897

Horga, G., Schatz, K. C., Abi-Dargham, A., \& Peterson, B. S. (2014). Deficits in predictive coding underlie hallucinations in schizophrenia. Journal of Neuroscience, 34(24), 8072-82. doi:10.1523/ JNEUROSCI.0200-14.2014

Ilankovic, L. M., Allen, P. P., Engel, R., Kambeitz, J., Riedel, M., Müller, N., \& Hennig-Fast, K. (2011). Attentional modulation of external speech attribution in patients with hallucinations and delusions. Neuropsychologia, 49(5), 805-812. doi:10.1016/j.neuropsychologia.2011.01.016

Javitt, D. C., Shelley, A. M., \& Ritter, W. (2000). Associated deficits in mismatch negativity generation and tone matching in schizophrenia. Clinical Neurophysiology, 111(10), 1733-1737. doi:10. 1016/S1388-2457(00)00377-1

Johns, L. C., Allen, P., Valli, I., Winton-Brown, T., Broome, M., Woolley, J., ... McGuire, P. (2010). Impaired verbal self-monitoring in individuals at high risk of psychosis. Psychological Medicine, 40(9), 1433-1442. doi:10.1017/S0033291709991991 
Johns, L. C., Rossell, S., Frith, C., Ahmad, F., Hemsley, D., Kuipers, E., \& McGuire, P. K. (2001). Verbal self-monitoring and auditory verbal hallucinations in patients with schizophrenia. Psychological Medicine, 31, 705-715. doi:10.1017/S0033291701003774

Johns, L. C., \& Van Os, J. (2001). The continuity of psychotic experiences in the general population. Clinical Psychology Review, 21(8), 1125-1141. doi:10.1016/S0272-7358(01)00103-9

Kambeitz-Ilankovic, L., Hennig-Fast, K., Benetti, S., Kambeitz, J., Pettersson-Yeo, W., O’daly, O., ... Allen, P. (2013). Attentional modulation of source attribution in first-episode psychosis: A functional magnetic resonance imaging study. Schizophrenia Bulletin, 39(5), 1027-1036. doi:10.1093/schbul/sbs101

Kreiman, J., \& Papcun, G. (1991). Comparing discrimination and recognition of unfamiliar voices. Speech Communication, 10(3), 265-275. doi:10.1016/0167-6393(91)90016-M

Kuznetsova, A., Brockhoff, P. B., \& Christensen, R. H. B. (2016). lmerTest: Tests in linear mixed effects models. $R$ Package Version 2.0-33. Retrieved from https://cran.r-project.org/package= lmerTest.

Larøi, F., Sommer, I. E., Blom, J. D., Fernyhough, C., Ffytche, D. H., Hugdahl, K., ... Waters, F. (2012). The characteristic features of auditory verbal hallucinations in clinical and nonclinical groups: State-of-the-art overview and future directions. Schizophrenia Bulletin, 38(4), 724733. doi:10.1093/schbul/sbs061

Larøi, F., \& Van Der Linden, M. (2005). Nonclinical participants' reports of hallucinatory experiences. Canadian Journal of Behavioural Science, 37(1), 33-43. doi:10.1037/h0087243

Launay, G., \& Slade, P. (1981). The measurement of hallucinatory predisposition in male and female prisoners. Personality and Individual Differences, 2(3), 221-234. doi:10.1016/0191-8869 (81) $90027-1$

Lavan, N., Scott, S. K., \& McGettigan, C. (2016). Impaired generalization of speaker identity in the perception of familiar and unfamiliar voices. Journal of Experimental Psychology: General, 145 (12), 1604-1614. doi:10.1037/xge0000223

Linden, D. E. J., Thornton, K., Kuswanto, C. N., Johnston, S. J., Van De Ven, V., \& Jackson, M. C. (2011). The Brain's voices: Comparing nonclinical auditory hallucinations and imagery. Cerebral Cortex, 21(2), 330-337. doi:10.1093/cercor/bhq097

McCarthy-Jones, S., Thomas, N., Strauss, C., Dodgson, G., Jones, N., Woods, A., ... Sommer, I. E. (2014). Better than mermaids and stray dogs? subtyping auditory verbal hallucinations and its implications for research and practice. Schizophrenia Bulletin, 40(Suppl 4), S275-S284. doi:10. $1093 / \mathrm{schbul} / \mathrm{sbu} 018$

McCarthy-Jones, S., Trauer, T., MacKinnon, A., Sims, E., Thomas, N., \& Copolov, D. L. (2014). A new phenomenological survey of auditory hallucinations: Evidence for subtypes and implications for theory and practice. Schizophrenia Bulletin, 40, 231-235. doi:10.1093/schbul/sbs156

McNeish, D. M., \& Stapleton, L. M. (2016). The Effect of Small Sample Size on Two-Level Model Estimates: A Review and Illustration. Educational Psychology Review, 28(2), 295-314. doi:10. 1007/s10648-014-9287-x

Meuleman, B., \& Billiet, J. (2009). A Monte Carlo sample size study: How many countries are needed for accurate multilevel SEM? Survey Research Methods, 3, 45-48.

Mørch-Johnsen, L., Nesvåg, R., Jørgensen, K. N., Lange, E. H., Hartberg, C. B., Haukvik, U. K., ... Agartz, I. (2017). Auditory cortex characteristics in schizophrenia: Associations with auditory hallucinations. Schizophrenia Bulletin, 43(1), 75-83. doi:10.1093/schbul/sbw130

Morrison, A. P. (2001). The interpretation of intrusions in psychosis: An integrative cognitive approach to hallucinations and delusions. Behavioural and Cognitive Psychotherapy, 29(3), 257-276. doi:10.1017/S1352465801003010

Mou, X., Bai, F., Xie, C., Shi, J., Yao, Z., Hao, G., ... Zhang, Z. J. (2013). Voice recognition and altered connectivity in schizophrenic patients with auditory hallucinations. Progress in NeuroPsychopharmacology and Biological Psychiatry, 44, 265-270. doi:10.1016/j.pnpbp.2013.03.006

Nakamura, K., Kawashima, R., Sugiura, M., Kato, T., Nakamura, A., Hatano, K., ... Kojima, S. (2001). Neural substrates for recognition of familiar voices: A PET study. Neuropsychologia, 39(10), 1047-1054. doi:10.1016/S0028-3932(01)00037-9 
Nayani, T. H., \& David, A. S. (1996). The auditory hallucination: A phenomenological survey. Psychological Medicine, 26(1), 177-189. doi:10.1017/S003329170003381X

Pell, M. D., \& Kotz, S. A. (2011). On the time course of vocal emotion recognition. PLoS ONE, 6(11), e27256. doi:10.1371/journal.pone.0027256

Pell, M. D., Rothermich, K., Liu, P., Paulmann, S., Sethi, S., \& Rigoulot, S. (2015). Preferential decoding of emotion from human non-linguistic vocalizations versus speech prosody. Biological Psychology, 111, 14-25. doi:10.1016/j.biopsycho.2015.08.008

Phillips, L. K., \& Seidman, L. J. (2008). Emotion processing in persons at risk for schizophrenia. Schizophrenia Bulletin, 34(5), 888-903. doi:10.1093/schbul/sbn085

Pinheiro, A. P., Rezaii, N., Rauber, A., Nestor, P. G., Spencer, K. M., \& Niznikiewicz, M. (2017). Emotional self-other voice processing in schizophrenia and its relationship with hallucinations: ERP evidence. Psychophysiology, 54(9), 1252-1265. doi:10.1111/psyp.12880

Pinheiro, A. P., Rezaii, N., Rauber, A., \& Niznikiewicz, M. (2016). Is this my voice or yours? The role of emotion and acoustic quality in self-other voice discrimination in schizophrenia. Cognitive Neuropsychiatry, 21(4), 335-353. doi:10.1080/13546805.2016.1208611

Pinheiro, A. P., Schwartze, M., \& Kotz, S. A. (2018). Voice-selective prediction alterations in nonclinical voice hearers. Scientific Reports, 8(1), 14717. doi:10.1038/s41598-018-32614-9

Raine, A. (1991). The SPQ: A Scale for the Assessment of Schizotypal Personality Based on DSMIII-R Criteria. Schizophrenia Bulletin, 17(4), 555-564. doi:10.1093/schbul/17.4.555

Rossell, S. L., \& Boundy, C. L. (2005). Are auditory-verbal hallucinations associated with auditory affective processing deficits? Schizophrenia Research, 78(1), 95-106. doi:10.1016/j.schres.2005.06.002

Schnakenberg Martin, A. M., Bartolomeo, L., Howell, J., Hetrick, W. P., Bolbecker, A. R., Breier, A., ... O'Donnell, B. F. (2018). Auditory feature perception and auditory hallucinatory experiences in schizophrenia spectrum disorder. European Archives of Psychiatry and Clinical Neuroscience, 268(7), 653-661. doi:10.1007/s00406-017-0839-1

Shea, T. L., Sergejew, A. A., Burnham, D., Jones, C., Rossell, S. L., Copolov, D. L., \& Egan, G. F. (2007). Emotional prosodic processing in auditory hallucinations. Schizophrenia Research, 90 (1-3), 214-220. doi:10.1016/j.schres.2006.09.021

Soares, A. P., Iriarte, Á., de Almeida, J. J., Simões, A., Costa, A., Machado, J., ... Perea, M. (2018). Procura-PALavras (P-PAL): A Web-based interface for a new European Portuguese lexical database. Behavior Research Methods, 50(4), 1461-1481. doi:10.3758/s13428-018-1058-z

Sohoglu, E., Peelle, J. E., Carlyon, R. P., \& Davis, M. H. (2012). Predictive Top-Down Integration of Prior Knowledge during Speech Perception. Journal of Neuroscience, 32(25), 8443-8453. doi:10. 1523/JNEUROSCI.5069-11.2012

Sommer, I. E. C., Diederen, K. M. J., Blom, J. D., Willems, A., Kushan, L., Slotema, K., ... Kahn, R. S. (2008). Auditory verbal hallucinations predominantly activate the right inferior frontal area. Brain, 131(12), 3169-3177. doi:10.1093/brain/awn251

Telles-Correia, D., Barbosa-Rocha, N., Gama-Marques, J., Moreira, A. L., Alves-Moreira, C., Saraiva, S., ... Haddock, G. (2017). Validation of the Portuguese version of the Psychotic Symptom Rating Scales (PSYRATS). Actas Espanolas de Psiquiatria, 45(2), 56-61.

Thoma, R. J., Meier, A., Houck, J., Clark, V. P., Lewine, J. D., Turner, J., ... Stephen, J. (2017). Diminished auditory sensory gating during active auditory verbal hallucinations. Schizophrenia Research, 188, 125-131. doi:10.1016/j.schres.2017.01.023

Tseng, H. H., Chen, S. H., Liu, C. M., Howes, O., Huang, Y. L., Hsieh, M. H., .. Hwu, H. G. (2013). Facial and Prosodic Emotion Recognition Deficits Associate with Specific Clusters of Psychotic Symptoms in Schizophrenia. PLoS ONE, 8(6), e66571.

Van Lancker, D., \& Kreiman, J. (1987). Voice discrimination and recognition are separate abilities. Neuropsychologia, 25(5), 829-834. doi:10.1016/0028-3932(87)90120-5

Van Lancker, D. R., Kreiman, J., \& Cummings, J. (1989). Voice perception deficits: neuroanatomical correlates of phonagnosia. Journal of Clinical and Experimental Neuropsychology, 11(5), 665674. doi:10.1080/01688638908400923

Van Os, J., Linscott, R. J., Myin-Germeys, I., Delespaul, P., \& Krabbendam, L. (2009). A systematic review and meta-analysis of the psychosis continuum: Evidence for a psychosis proneness- 
persistence-impairment model of psychotic disorder. Psychological Medicine, 39(2), 179-195. doi:10.1017/S0033291708003814

Waters, F., Allen, P., Aleman, A., Fernyhough, C., Woodward, T. S., Badcock, J. C., ... Larøi, F. (2012). Auditory hallucinations in schizophrenia and nonschizophrenia populations: a review and integrated model of cognitive mechanisms. Schizophrenia Bulletin, 38(4), 683-93. doi:10. 1093/schbul/sbs045

Waters, F., \& Fernyhough, C. (2017). Hallucinations: A Systematic Review of Points of Similarity and Difference Across Diagnostic Classes. Schizophrenia Bulletin, 43(1), 32-43. doi:10.1093/ schbul/sbw132

Watson, L. A., Dritschel, B., Obonsawin, M. C., \& Jentzsch, I. (2007). Seeing yourself in a positive light: Brain correlates of the self-positivity bias. Brain Research, 1152(1), 106-110. doi:10.1016/j. brainres.2007.03.049

Woodruff, P. W. R. (2004). Auditory hallucinations: Insights and questions from neuroimaging. Cognitive Neuropsychiatry, 9(1-2), 73-91. doi:10.1080/13546800344000165

Zarate, J. M., Tian, X., Woods, K. J. P., \& Poeppel, D. (2015). Multiple levels of linguistic and paralinguistic features contribute to voice recognition. Scientific Reports, 5, 11475. doi:10.1038/ srep 11475 